\title{
Application of free-listing in identifying desirable foods and their accessibility in an urban nonprofit supermarket
}

\author{
Kaitlyn Harper, ${ }^{\text {* }}$ Emma C. Lewis, ${ }^{\mathrm{b}}$ Lisa Poirier, ${ }^{\mathrm{c}}$ Bengucan Gunen, ${ }^{\mathrm{d}}$ \\ Antonio Trujillo, ${ }^{e}$ and Joel Gittelsohn ${ }^{\mathrm{f}}$ \\ Johns Hopkins University Bloomberg School of Public Health
}

Submitted July 22, 2020 / Revised September 27 and November 1, 2020 / Accepted November 1, 2020 /

Published online March 31, 2021

Citation: Harper, K., Lewis, E. C., Poirier, L., Gunen, B., Trujillo, A., \& Gittelsohn, J. (2021). Application of free-listing in identifying desirable foods and their accessibility in an urban nonprofit supermarket. Journal of Agriculture, Food Systems, and Community Development, 10(2), 473-487. https://doi.org/10.5304/jafscd.2021.102.048

Copyright (C) 2021 by the Author. Published by the Lyson Center for Civic Agriculture and Food Systems. Open access under CC-BY license.

\begin{abstract}
There is a gap in the literature regarding the specific methods used by supermarkets to engage community members in operations and decisionmaking processes. Free-listing is an engagement
\end{abstract}

a* Corresponding author: Kaitlyn Harper, Doctoral candidate, Department of International Health, Johns Hopkins University Bloomberg School of Public Health; 615 North Wolfe Street, Baltimore, MD 21205 USA; +1-503-956-8071; kharpe14@jhu.edu

${ }^{\mathrm{b}}$ Emma C. Lewis, Doctoral student, Department of International Health, Johns Hopkins University Bloomberg School of Public Health.

${ }^{c}$ Lisa Poirier, Research Assistant, Department of International Health, Johns Hopkins University Bloomberg School of Public Health.

d Bengucan Gunen, Doctoral student, Department of International Health, Johns Hopkins University Bloomberg School of Public Health.

Bengucan Gunen is now at the Department of Community Health \& Prevention, Drexel University Dornsife School of Public Health; 3215 Market St.; Philadelphia, PA 19104 USA. method that allows individuals to list all possible items associated with a particular topic or domain. This study explores the application of free-listing as a method to assess the availability and affordability of food items at DMG Foods, a nonprofit supermarket in Baltimore, Maryland, to assist with making stocking decisions and increasing store use.

e Antonio Trujillo, Associate Professor, Department of International Health, Johns Hopkins University Bloomberg School of Public Health.

f Joel Gittelsohn, Professor, Department of International Health, Johns Hopkins University Bloomberg School of Public Health; jgittel1@jhu.edu

\section{Funding Disclosure}

Research is supported by the Johns Hopkins Urban Health Institute Graduate Student-Community Research or Program Development Projects.

\section{Acknowledgments}

We would like to acknowledge and express our gratitude for our partners at DMG Foods for their support, including Major Gene Hogg and Amy Middleton, and the community members who participated in the study. 
Twenty residents in central northeast Baltimore participated in free-listing desirable foods and frequented supermarkets. All selected participants were over 18 years of age, Black, and regularly shopped in the central northeast region of Baltimore. We calculated the saliency of food items and stores based on an item's frequency and order of mention in the free-listing. We then conducted store observations of the top salient stores three times at three-week intervals to identify the availability and accessibility of the top salient food items. Fifteen items had saliency scores greater than 0.1 and were retained for observation. Five stores had saliency scores greater than 0.1 and were within a five-mile $(8-\mathrm{km})$ radius from DMG Foods. Larger supermarkets carried the widest variety of salient items, and the prices of items varied between stores, highlighting the importance of communitydriven stocking for smaller supermarkets. Freelisting is a simple engagement method that store managers with limited research experience can use to identify foods that are desirable to residents of the community, ultimately leading to improved community food environments and increased store success.

\section{Keywords}

Free-Listing, Nonprofit Supermarket, Food Environment, Food Access

\section{Introduction and Literature Review}

In the United States, low-income communities and communities of color are disproportionately affected by food insecurity and diet-related diseases, in part due to limited access to nutritious and desirable foods (Gamblin, 2017; Petersen, Pan, \& Blanck, 2019). Residential areas with limited access to affordable nutritious foods and areas with a high ratio of unhealthy food sources (e.g., fast food restaurants, carry-outs) to healthy food sources (e.g., supermarkets) have been termed "food deserts" and "food swamps," respectively (CookseyStowers, Schwartz, \& Brownell, 2017). Living in a food desert or swamp is associated with having a poorer diet and increased risk of chronic disease (Cooksey-Stowers et al., 2017; Ghosh-Dastidar et al., 2014; Hager et al., 2017).

Establishing new supermarkets has been a key strategy for improving low food access. The Healthy Food Financing Initiative (HFFI), created by Congress in 2010, planned to reduce the number of food deserts and swamps by opening or expanding 1,500 for-profit supermarkets, nonprofit supermarkets, and convenience stores in these areas (U.S. Department of Health and Human Services, 2019). However, this initiative was largely unsuccessful: only one-quarter of the number of supermarkets planned by HFFI were opened, and many of the supermarkets that opened during this time closed within five years. Previous research has shown that the success of new supermarkets depends in part on community engagement during planning and development (Brinkley, Glennie, Chrisinger, \& Flores, 2019). Community engagement has also been shown to improve healthy food availability, sales, and consumption in interventions (Gittelsohn, Rowan, \& Gadhoke, 2012; Gudzune, Welsh, Lane, Chissell, Anderson Steeves, \& Gittelsohn, 2015).

Supermarkets developed by nonprofit organizations through the HFFI engaged community members in the planning process better and were more successful than those developed for profit by other entities (e.g., city or state government, commercial retailers) (Brinkley et al., 2019). Nonprofit supermarkets can be found in numerous cities across the U.S. The goal of many of these stores is to provide affordable foods for the community, as well as social services such as nutritional guidance, shopping education, and workforce development. However, nonprofit supermarkets face many challenges compared to larger chain supermarkets, including low customer turnout attributed to small store size, reduced selection, and inconsistent pricing and promotional strategies. There also seems to be a perceived lack of safety of the neighborhoods surrounding many nonprofit supermarkets (Yao, Hillier, Wall, DiSantis, 2019).

The Salvation Army established its first nonprofit supermarket, DMG Foods, in Baltimore, MD, in 2018. Similar to other nonprofit supermarkets, DMG Foods experiences challenges with store use (e.g., limited customer turnout) as well as low purchasing per customer visit. A recent mixedmethods study explored reasons for the low usage of DMG Foods and identified factors such as high 
prices, unclear signage and advertising, and lack of product variety (Daniel et al., 2021). Although DMG Foods has a large selection of foods in store, they may lack foods that are desired by or culturally relevant to residents in the surrounding community.

There are numerous engagement strategies that may be used to collect information from community members, such as surveys, focus groups, individual interviews, and free-listing. Free-listing is a qualitative data collection method that is used to gather information about a particular cultural domain or topic (Weller \& Romney, 1988). In freelisting, researchers ask a question (e.g., "What are all the different types of X?"), and participants list out all items they perceive to be part of that domain (Quinlan, 2017). Data collected from freelisting allows researchers to make inferences about the "saliency" of items within a domain, or which items are better known or important to the study population, with a relatively small sample size. Saliency scores can be calculated from the item's frequency (how many participants mentioned the item) and order of mention in the free-listing (first, middle, last). Saliency scores vary from 1 (highest) to 0 (lowest), and highly scoring items are those that are mentioned more often and are positioned higher on participants' lists. In the context of research, free-listing has been used extensively to assess categories of foods (e.g., junk food, culturally relevant foods, etc.) (Gittelsohn et al., 2016). However, to our knowledge, there have been no other studies in which free-listing has been used to identify foods that are desirable to customers specifically in retail settings.

There is a gap in the literature regarding the specific methods used by nonprofit supermarkets such as DMG Foods to engage community members in operations and decision-making processes. To our knowledge, no studies have explored how nonprofit supermarkets decide which items to stock or whether the items they stock are desirable to the surrounding community. Therefore, the overall goal of the present study was to explore foods that were desirable to community members and assess the availability and affordability of these items at DMG Foods in order to assist with making stocking decisions and increasing store use. The specific aims of this study were to: (1) explore freelisting as a simple method to be used by nonprofit supermarkets to identify salient foods for residents of the surrounding community; (2) identify foods that are salient for Black residents living in central northeast Baltimore; and (3) examine access to the identified foods at DMG Foods and other community supermarkets. This research group has a strong and long-lasting partnership with DMG Foods, and the findings from this study informed recommendations for current in-store stocking strategies and for planning of future supermarkets developed by the Salvation Army.

\section{Applied Research Methods}

\section{Setting Description}

In Baltimore City, there are approximately 871 retail food stores, of which $47(5 \%)$ are supermarkets, 633 are small grocery and corner stores $(73 \%), 185$ are convenience stores $(22 \%)$, and 6 (less than 1\%) are public markets (Misiaszek, Buzogany, \& Freishtat, 2018). Nevertheless, almost one-quarter of Baltimore residents live in food deserts, which were renamed Healthy Food Priority Areas (HFPA) by the Baltimore City Department of Planning in 2018. HFPAs are defined as areas where there is low availability of healthy foods, the median household income is at or below $185 \%$ of the Federal Poverty Level, over 30\% of households do not have a vehicle available, and the average distance to a supermarket is over one-quarter of a mile $(.4 \mathrm{~km})$ (Misiaszek et al., 2018). Thirty-one percent of Black Baltimore residents live in a HFPA compared to only $8.9 \%$ of White and $6.9 \%$ of Asian residents. This study was conducted in the central northeast region of Baltimore. Free-listing data were collected at DMG Foods, which is located in the Waverly neighborhood. The store is located within two blocks of an HFPA, and the neighborhood surrounding the store is primarily low-income (median income $\sim \$ 30,000$ ) and consists of $75 \%$ Black residents (Baltimore City Health Department, 2017).

\section{Data Collection}

Data were collected in two phases: (1) free-listing and (2) store observations. Free-listing was used to 
identify items within a domain most salient to the study population. The research team developed a set of three complementary open-ended questions, pilot-tested the questions with five individuals, and edited the wording of the questions based on responses from the pilot test. Considerable attention was given to the wording of the first question, how to select the appropriate term to identify salient foods. The questions were refined specifically to reflect foods that are purchased frequently, rather than foods that were eaten only on special occasions. Responses from pilot testing were not included in the final results. The final questions included: (1) "What are all the different foods that are special or meaningful to you, your friends, and your family?"; (2) "How often do you, your friends, and your family eat these foods?"; and (3) "Where do you, your friends, and your family typically purchase these types of foods?" Probing (e.g., "Can you think of any other foods that are special or meaningful?") was used to create a complete list of foods. Data collectors were graduate students with experience in qualitative research methods who were trained in free-listing methods by the principal investigator $(J G)$ of the study. Participants freelisted answers to the first and third questions orally while the data collectors wrote down each item listed; free-listing activities were not audio-recorded. The second question was asked specifically regarding the items listed in the first question. The saliency of food items and stores was determined based on an item's frequency and order of mention in the free-listing.

The 15 most salient free-listed food items and five most salient free-listed stores within a five-mile $(8-\mathrm{km})$ radius of DMG Foods were identified using saliency analysis, as described in Data Analysis below. A direct observation tool was developed to collect data on each of the items at each of the five stores. All observation sheets were composed of a table with one row for each of the food items. One item, collard greens, was not specified by participants as canned or fresh and was therefore listed twice to account for both, resulting in 16 rows total. Columns included presence or absence of the item, quantity of present items ( $<5$ items, 5-10 items, $>10$ items), item shelf location (top shelf, eye-level, below eye-level, bottom shelf), item price listed (e.g., US\$4.99), and item price per unit (e.g., US $\$ 0.49$ cents per pound). Three observations were conducted in each of the five stores approximately three weeks apart in order to account for (1) short-term price changes and (2) items that may have sold out at a certain time. For items that had multiple brands (e.g., canned greens), the lowestcost item was recorded at all stores. For produce items with multiple varieties (e.g., apples: Red Delicious, Gala, Fuji; tomatoes: Roma, on-the-vine, cherry), a specific variety was chosen to represent the produce item if it was found in all stores where the item was present. Similarly, 80\% lean ground beef was selected because it was found in all stores where the item was present. Only one food from the top 15 salient items - spaghetti-contained multiple ingredients, and for this item, data were collected on the lowest-priced brand of spaghetti sauce.

\section{Study Participants}

Twenty Black adults in central northeast Baltimore participated in the free-listing activity. Half $(n=10)$ of the participants were male and half $(n=10)$ were female. Participants were selected from two community locations - a recreation center and a supermarket - in July to October 2019 using convenience sampling. Participants were eligible for inclusion if they (i) identified as Black, (ii) were over the age of 18, and (iii) regularly shopped for food in the Waverly neighborhood. No demographic information was collected from participants except for sex.

\section{Data Analysis}

Saliency analysis was conducted for items from two free-lists (food items and stores), using the AnthroTools package (Purzycki \& Jamieson-Lane, 2017) in R (R Core Team, 2020). Four free-lists were used to pilot test the instrument, and after subsequent changes were made, all four were excluded from analysis (final $n=20$ ). Saliency was determined using Smith's $\mathrm{S}$, a saliency index calculated by the equation: $S_{j}=\left(\left(L-R_{j}+1\right) / L\right) / N$, where $L$ is the list length, $R_{j}$ is the rank of item $J$ in the list (first $=1$ ), and $\mathrm{N}$ is the number of participants (Smith \& Borgatti, 1997). Saliency scores range from 1 (high) to 0 (low), and there are no standardized cutoff 
points to determine which items should be retained. In this study, a cutoff point of 0.1 was used for retention. This cutoff allowed us to obtain feasible numbers of food items $(\leq 20)$ and stores $(\leq 5)$ for observation, which researchers determined in the planning stage of the study. Additionally, the frequency of items eaten was grouped into six categories: (1) rarely/special occasions; (2) 1-3 times/ month; (3) 1-2 times/week; (4) 3-4 times/week; (5) 5-6 times/week; (6) every day. We calculated the average frequency score per item for each Salient item $(\mathrm{S}>0.1)$, as well as pairwise comparisons for the number of items present between stores using independent 2-sample t-tests with Bonferroni correction (alpha $=0.01)$.

We then calculated the mean and standard

\section{Figure 1. Saliency of Food Items with the Highest Smith's S Salience Index Scores from Free-listing Activity $(N=20)$}

Figure 1 displays all items with saliency scores above the cutoff point of 0.1 (range: $0.10-0.40$ ). These 15 items were retained for store observation. Since collard greens are often purchased fresh and canned, it was split into two distinct items for store observation, creating a total of 16 observed food items.

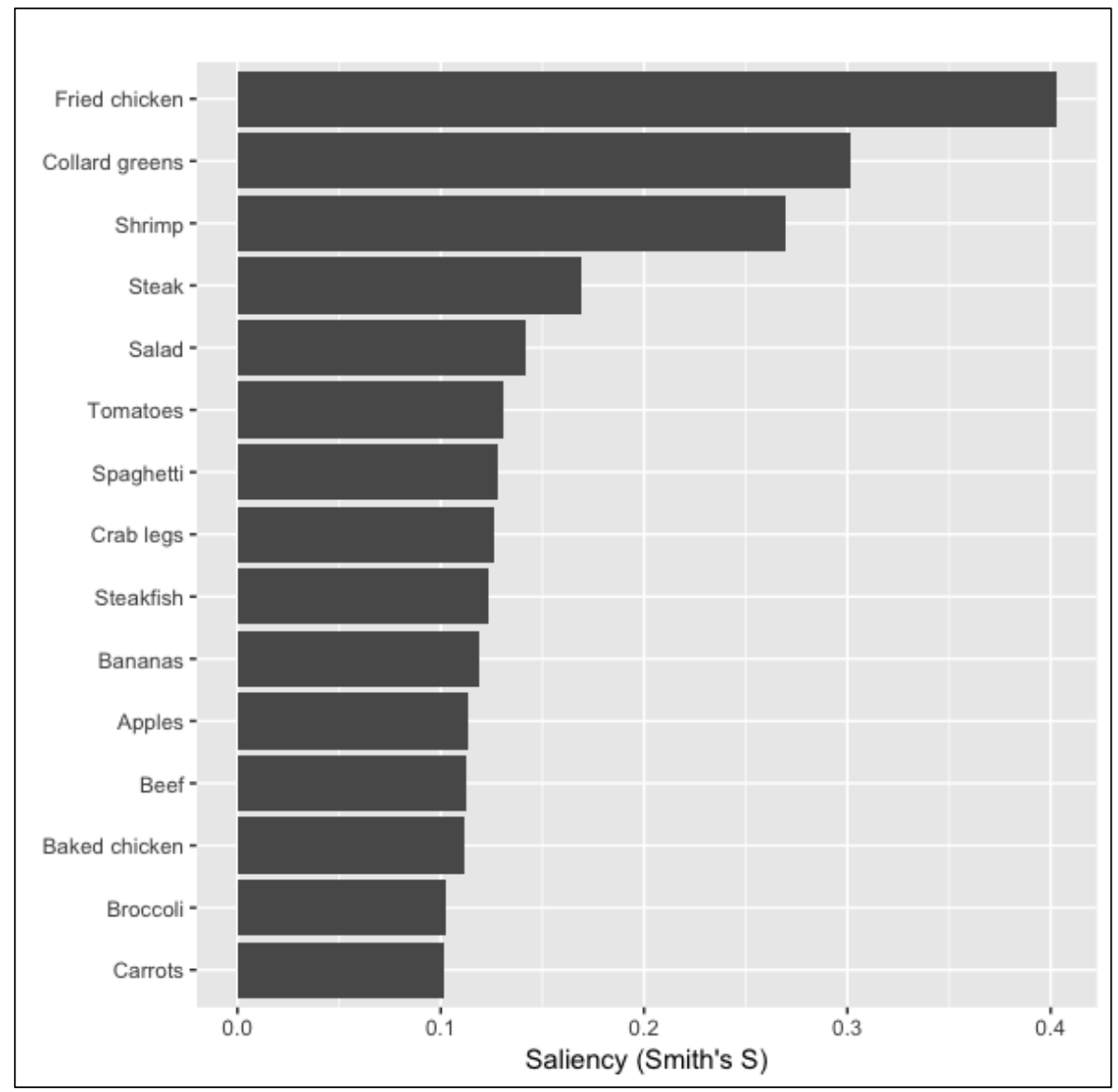

deviation of the price of each item across three store visits. Analysis of variance (ANOVA) was used to determine if there was a significant difference in mean price between stores using an alpha level of 0.05. Pairwise comparisons for each item were calculated between stores using independent 2-sample t-tests with Bonferroni correction (alpha $=0.01)$. Additionally, the average number of items present per visit in each store was calculated, and pairwise comparisons between each store were calculated using Pearson's chi-squared test with Bonferroni correction (alpha $=0.01$ ).

\section{Ethical Approval}

Approval for the study was obtained from the institutional review board at the Johns Hopkins

Bloomberg School of Public Health. All participants were provided with verbal and written details about the study at recruitment, and verbal informed consent was obtained from all participants.

\section{Results}

\section{Salient Food Items and Stores}

Participants identified 146 food and beverage items during the free-listing activity (see Appendix A), with a range of saliency scores between 0.403 and 0.003 . Of the total number of items, $33(23 \%)$ were mentioned by three or more participants, and 14 $(9 \%)$ were mentioned by four or more participants. Figure 1 shows the 15 items that had saliency scores greater than 0.1 and the three items-fried chicken $\left(S_{j}=0.40\right)$, collard greens $\left(S_{j}=0.30\right)$, and shrimp $\left(S_{j}=0.27\right)$-that had 
saliency scores above 0.2 . The frequency of consumption score for each of the salient items ranged between 2 (1-3 times/month) and 4.4 (3-4 times/ week), with a mean and median score of 3.3 (1-2 times/week).

Participants also identified 35 retail food stores during the free-listing activity with a range of Saliency scores between 0.005 and 0.703 (Appendix B). Of the total number of stores, 9 stores $(26 \%)$ were mentioned by three or more participants, and 6 stores $(17 \%)$ were mentioned by four or more participants. Six stores had saliency scores above 0.1 -Giant $\left(S_{j}=0.70\right)$, DMG Foods $\left(S_{j}=0.47\right)$, Safeway $\left(S_{j}=0.18\right)$, Aldi $\left(S_{j}=0.15\right)$, Walmart $\left(S_{j}=0.12\right)$, and Family Dollar $\left(S_{j}=0.11\right)$, as shown in Figure 2. One store (Walmart) was outside a five-mile $(8-\mathrm{km})$ radius from DMG Foods and was therefore excluded from the store observations.

\section{Availability and Price of Salient Food Items by Store}

The average number of salient food items present at each of the five stores was variable, as shown in Figure 3. Giant had the highest number of salient foods $(n=15.3$; $96 \%)$, followed by Safeway $(n=15.0,93 \%)$, DMG Foods $(n=10.7,67 \%)$, Aldi $(n=10.0,63 \%)$, and Family Dollar $(n=2.3$, $14 \%$ ). The number of food items present between all stores was significantly different except between Giant/ Safeway and DMG Foods/Aldi. Additionally, not all food items were present during every store observational visit. Some items, such as shrimp, were only available one time during observations at Aldi and Family Dollar, and others, such as "steakfish" (hake fish), were only available during one observation at one store throughout the entire data collection period.

Of the 16 items, 10 had prices that were significantly different between stores, as shown in Table 1. For example, of the four stores where apples were observed (i.e., Aldi, DMG Foods, Giant, and Safeway), the price of apples was significantly lower at Aldi and DMG Foods compared to Giant, but there were no significant differences in prices between Aldi, DMG Foods, and Safeway. DMG Foods and Giant had the greatest number of lowest-priced items ( $n=5$ for each), followed by Aldi $(n=4)$. Safeway and Family Dollar had the

\section{Figure 2. Saliency of Stores with the Highest Smith's S Salience Index Scores from Free-listing Activity $(N=20)$}

Figure 2 displays the five stores with saliency scores above the cutoff point of 0.1 (range: 0.11-0.70). These stores were retained for observation of the top 16 salient food items.

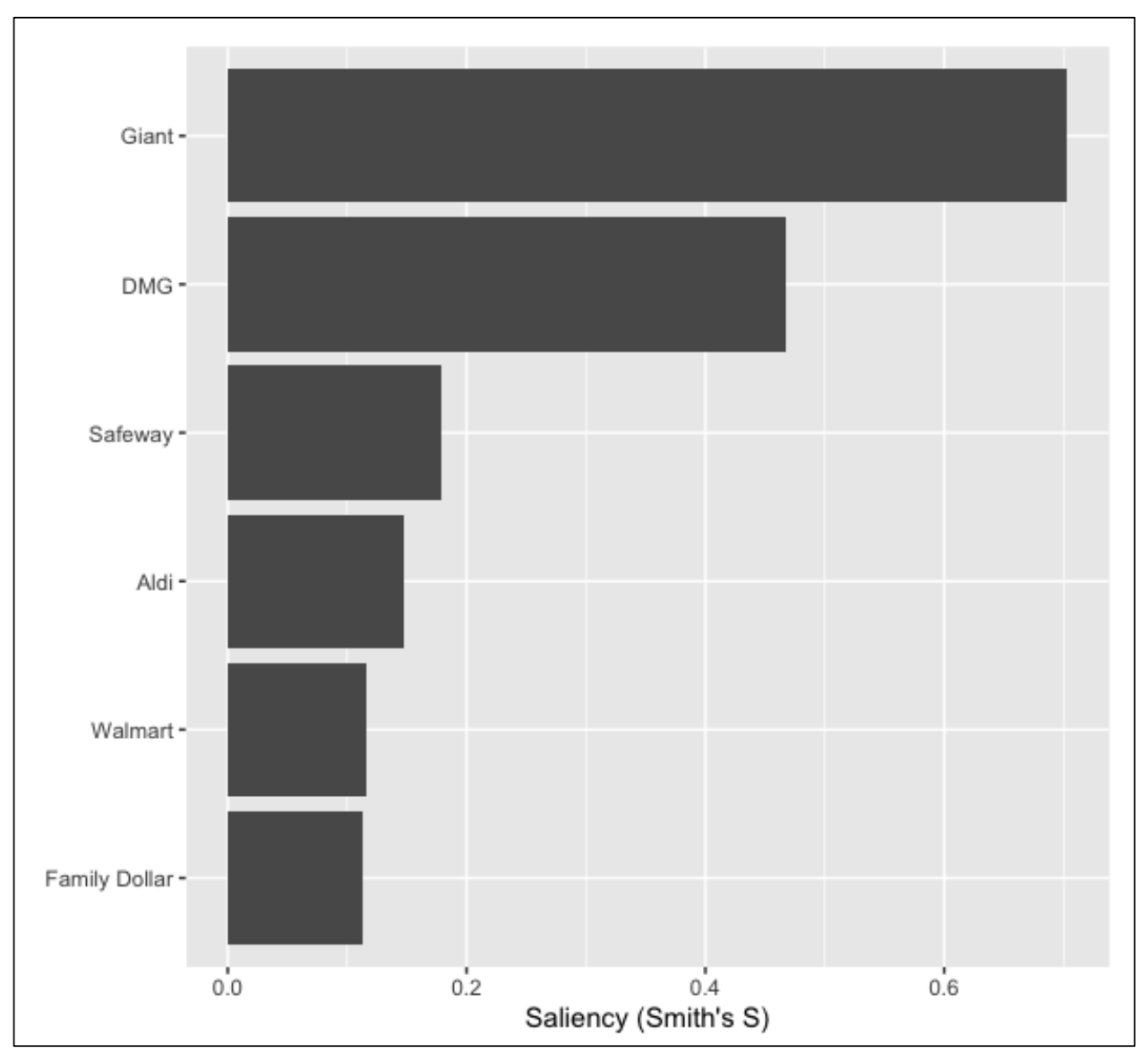


smallest number of lowest priced items $(n=2$ for each). The proportion of lowest-priced items depended greatly on the number of items present in the store. For example, Family Dollar had the highest proportion of lowest-priced items $(n=2$, $67 \%$ ) but only had three items present during store observations. In contrast, Safeway had the smallest proportion of lowest-priced items $(n=2,13 \%)$ but had an average of 15 items present during store observations.

Finally, Table 1 shows that the variability in price depended on the item and the store. For example, numerous items had standard deviations of zero, indicating that prices did not change between the three store observations. Safeway had the greatest number of items with the highest variability $(n=6,40 \%)$, followed by DMG Foods $(n=4,31 \%)$, Giant $(n=3,19 \%)$, Aldi $(n=2,18 \%)$, and Family Dollar $(n=0)$. Some items, such as spaghetti sauce, had very little variability between stores (standard deviation (sd) range: $\$ 0-0.05 / \mathrm{oz}$ ). Other items, such as shrimp and strip steak, had high variability between stores (shrimp sd range: $\$ 0-1.53 / \mathrm{lb}$; strip steak sd range: $\$ 0-6.08 / \mathrm{lb}$ ).

\section{Discussion}

The goal of this study was to use free-listing to identify and examine accessibility (i.e., availability and price) of salient food items for Black residents living in central northeast Baltimore. The use of free-listing methods in this study suggest that the application of this method is cost-effective and time-efficient. Existing nonprofit supermarkets can use this method to identify foods that may be missing from their inventory. Additionally, nonprofit organizations that are in the process of developing new supermarkets can use it to identify foods that may be important for the surrounding

\section{Figure 3. Average Number of Items per Store, Measured by Three Consecutive Observations with Three- Week Intervals}

Researchers observed each store on three occasions, approximately three weeks apart. During each observation, researchers looked for 16 items and counted the number of items that were present. The average number of items observed at each score was calculated by adding the number of items observed at each store over the three visits and dividing by three. This figure displays the average number of items present at each store and compares the stores to each other using independent 2-sample t-tests with Bonferroni correction (alpha=0.01). NS indicates not significant.

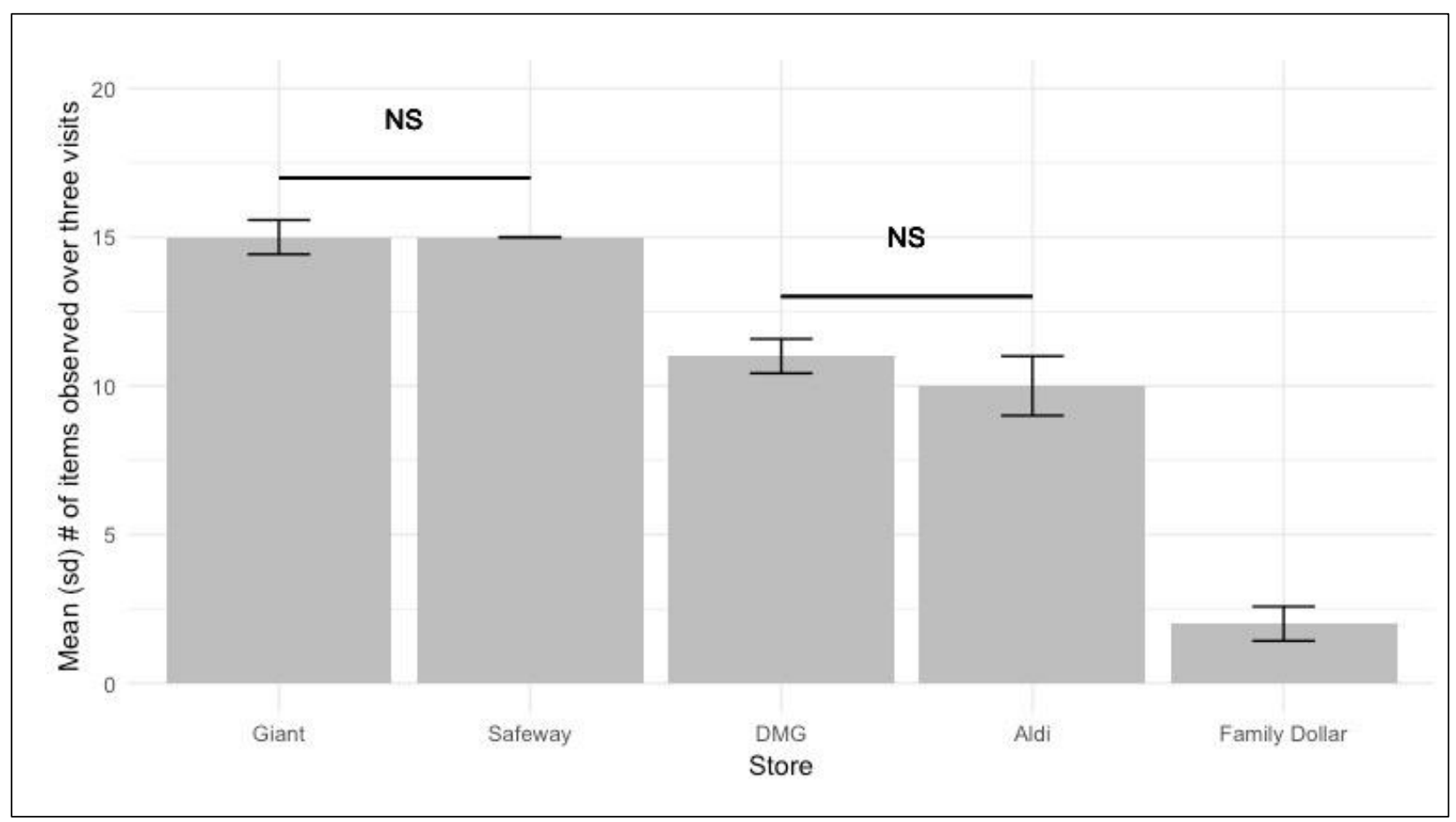


Table 1. Differences in the Prices per Unit of Top Salient Items by Store $(N=16)$, Measured by Three Consecutive Observations with Three-week Intervals

\begin{tabular}{|c|c|c|c|c|c|c|}
\hline Item (unit) & Aldi & DMG Foods & Family Dollar & Giant & Safeway & $p$ \\
\hline Apples (Ib) & $1.00(0.02)^{b}$ & $0.99(0)^{d}$ & - & $1.76(0.06)^{b, d}$ & $2.16(0.29)$ & $<0.001$ \\
\hline Baked chicken (Ib) & - & - & - & $6.66(0.58)$ & $6.99(0)$ & 0.374 \\
\hline Bananas (lb) & $0.44(0)^{b, c}$ & $0.34(0.08)$ & - & $0.59(0) \mathrm{b}$ & $0.59(0)^{c}$ & $<0.001$ \\
\hline Broccoli (Ib) & $1.62(0.15)$ & $1.25(0.35)$ & - & $1.79(0.17)$ & $2.32(0.29)$ & 0.008 \\
\hline Canned greens (oz) & - & $0.12(0.04)$ & $0.07(0)$ & $0.09(0.01)$ & $0.12(0.05)$ & 0.215 \\
\hline Carrots (Ib) & $0.98(0.53)$ & $0.97(0.04)$ & - & $0.82(0.14)$ & $0.96(0.05)$ & 0.874 \\
\hline Crab legs (Ib) & - & - & - & $10.99(0)^{f}$ & $11.99(0)^{f}$ & $<0.001$ \\
\hline Fresh collard greens (Ib) & $3.72(0.75)$ & $2.49(N A) d, e$ & - & $1.49(0)^{d}$ & $1.49(0)^{\mathrm{e}}$ & 0.002 \\
\hline Fried chicken (Ib) & - & $7.75(0.36)$ & - & $7.99(0)^{6}$ & $6.99(0)^{6}$ & 0.001 \\
\hline Ground beef (lb) & $3.17(0.03)^{a, c}$ & 1.99 (NA) a,d,e & - & $4.32(0.29)^{d}$ & $5.16(0.29) \mathrm{c}, \mathrm{e}$ & $<0.001$ \\
\hline Iceberg lettuce (each) & $1.36(0.06)^{c}$ & $1.67(0.1) \mathrm{e}$ & - & $1.88(0.19)^{f}$ & $2.49(0) c, e, f$ & $<0.001$ \\
\hline Spaghetti sauce (oz) & $0.04(0)$ & $0.06(0)$ & $0.04(0.01)$ & $0.06(0)$ & $0.10(0.05)$ & 0.068 \\
\hline Shrimp (Ib) & 6.72 (NA) & $7.99(0)$ & 8.64 (NA) & $7.32(0.58)$ & $8.32(1.53)$ & 0.486 \\
\hline Steakfish (Ib) & - & - & - & 10.99 (NA) & - & $\mathrm{N} / \mathrm{A}$ \\
\hline Strip steak (Ib) & $8.89(0)^{b}$ & $3.79(1.7)$ & - & $14.49(0.87)^{b}$ & $11.99(6.08)$ & 0.046 \\
\hline Tomatoes (Ib) & $1.05(0.63)^{\mathrm{c}}$ & $3.32(1.15)$ & - & $1.82(0.29)$ & $3.82(0.76)^{c}$ & 0.008 \\
\hline
\end{tabular}

Standard deviations of zero indicate that all items were the exact same price at all three observations. Standard deviations denoted with NA indicate that the item was only present during one observation.

$P$-values calculated by ANOVA were assessed using a significance level of 0.05.

Superscript numbers indicate significant differences between stores: a DMG vs. Aldi; b Giant vs. Aldi; c Safeway vs. Aldi; d Giant vs. DMG; e Safeway vs. DMG; ${ }^{\mathrm{f}}$ Safeway vs. Giant. Pvalues calculated using two-sided pairwise comparisons with unpooled variances. Significance was determined using a Bonferroni-adjusted significance level of 0.01. Bold prices (sd) represent the lowest-price store for each item. 
neighborhood. Free-listing could easily be incorporated into other supermarket planning and development activities that are already in use, such as town hall meetings, which are often facilitated by nonprofit organizations to discuss various issues (e.g., building appearance and layout, hiring practices, and product offerings) (Brinkley et al., 2019).

Additionally, the free-listing method has many advantages as a standalone method. For example, as opposed to surveys, free-listing is open-ended and therefore does not limit the number of items or the content collected. This is particularly important in the retail setting - and especially in the development of new stores in food deserts-where store managers may not be familiar with the food preferences of the surrounding community. Thus, free-listing allows the discovery of foods that may not be previously recognized by store managers as important. Another advantage of free-listing is that it allows for rapid data collection in a short length of time and does not require prior expertise in data collection. Compared to activities such as focus groups and interviews, free-lists can be collected as customers walk or out of the store and take less than 10 minutes to complete. In our study, each participant spent less than five minutes completing the free-listing activity, and we were able to recruit participants easily at the entrance of the store. Customers were eager to participate in the study once we explained that the information would be used to provide DMG Foods with recommendations on improved stocking and pricing. Its simplicity makes the free-listing method ideal for store managers who may have limited or no experience with research techniques. Finally, the method does not require transcription and analysis of audio-recorded activities, nor does it require extensive knowledge of data analysis techniques. Smith's S can be calculated in a spreadsheet or common statistical software using the formula we presented above.

Free-listing can also help address some of the challenges faced by small and nonprofit supermarkets, such as reduced selection and inconsistent promotional strategies. For example, a store may have numerous types of dairy milk, but customers who desire to purchase nondairy milk may view the milk selection as limited. Free-listing can help stores—particularly small stores—make decisions on how to use their limited stocking space. Freelisting helps identify items that will expand their selection (e.g., different brands, sizes, etc.) of preferred foods while reducing the selection of foods that may not be as desirable. Additionally, knowing which foods are meaningful to customers can help stores highlight and promote preferred foods. Previous interviews with customers from DMG Foods as well as store observations have shown that excess promotional signage is confusing to customers (Daniel et al., 2021). Free-listing can help stores identify a set of foods for promotion while reducing signage on other products. Finally, since freelisting is a time-efficient and straightforward way to collect information, stores may choose to repeat the free-listing process multiple times throughout the year to collect information on seasonal foods.

We also explored the accessibility (defined as ready availability and affordable price) of the identified preferred food items in DMG Foods and other nearby supermarkets. This was a natural next step, since we wanted to use free-listing to inform recommendations to DMG Foods, but the freelisting questions did not provide sufficient in-depth information on availability or price. We used the 15 most salient items identified through free-listing because we found that they were regularly consumed by participants (1-2 times/week), providing evidence that these are important foods for supermarkets to stock consistently. Observations of DMG Foods and neighboring stores highlighted differences in both availability and price. Item availability was observed on a spectrum, where larger chain supermarkets carried all or most salient items, midsized supermarkets (including DMG Foods) carried fewer items, and Family Dollar carried the fewest number of items. These results are supported by previous research that shows that small supermarkets and dollar stores carry a smaller selection of food items, particularly of healthier food items (Caspi, Pelletier, Harnack, Erickson, \& Laska, 2016; Laska, Borradaile, Tester, Foster, \& Gittelsohn, 2010). These findings are unsurprising, given that smaller stores have limited capacity to stock a wide variety of items. Thus, it is imperative that new and existing smaller stores use their limited capacity to stock food items that are preferred by community members, again highlighting the im- 
portance of free-listing. Additionally, the store observation process was straightforward and feasibly could be adapted by store managers to track products over time to ensure that their prices are competitive (matching or lower) with nearby supermarkets. For example, it took approximately 10 minutes to observe all items in a single store, and comparisons of prices could be done using a spreadsheet or similar programs.

Based on the findings from our study, we developed three recommendations for DMG Foods to increase store usage. First, DMG Foods should continue to stock the salient items identified in this study, and stock the remaining three salient items (baked chicken, crab legs, and steakfish) that were not available at the time of observations. Second, DMG Foods should reduce the prices of salient foods by $15-30 \%$ for items that were not already priced lower compared to other stores. Although DMG Foods did carry most of the salient items identified by participants, their prices were not always lower than nearby stores. Decreases in this range would allow all but one salient item (tomatoes) to have the lowest price of all five stores. Lowering the prices of salient items could help improve customer turnout and is a common practice used by stores known as "loss leader pricing” (Hess \& Gerstner, 1987). Loss leader pricing assumes that desirable items (i.e., the leaders) sold at a reduced price will entice customers to visit the store, which in turn leads to increased purchasing of other items. We recognize that lowering the prices of salient items would likely lead to decreases in profits due to the marginal costs associated with these items, which are often determined by manufacturers and wholesalers. DMG Foods is already operating at a loss each month, and further reductions in prices may not be feasible for the sustainability of the store. Therefore, our third recommendation is that DMG Foods should evaluate its current relationship with wholesalers and potentially partner with wholesalers that provide salient food items for lower prices.

This is the first study to use free-listing methods to help a supermarket identify foods that are important to community members. To our knowledge, only one other study has assessed the accessibility of culturally relevant fruits and vegetables in supermarkets within communities of color; it found that over half of stores in predominantly Black neighborhoods carried only $6 \%$ of culturally relevant fruits and vegetables (Grigsby-Toussaint, Zenk, Odoms-Young, Ruggiero, Moise, 2010). That study emphasized the need to create interventions and develop measurement tools that include culturally relevant foods, but did not provide guidance on how to identify these foods. Free-listing is a quick and straightforward method that can lead to increased community engagement in future studies that aim to assess the prevalence of culturally relevant foods in predominantly Black neighborhoods.

Community engagement strategies should be used whenever new supermarkets are developed, and particularly when they are developed in food deserts and food swamps. People of color are disproportionately affected by negative health outcomes due to living in food deserts or food swamps, a direct result of historic systemic racism, including white flight, residential redlining, and "supermarket redlining" (Eisenhauer, 2001; Zhang \& Debarchana, 2016). We recognize that there is no silver bullet to solve the issue of low food access and unavailability of healthy foods in communities of color. Moreover, we believe that developing equitable supermarket solutions can only be done when led by fully compensated members of the community, with economic growth pathways built into the process and institution, and that anything less upholds white supremacy culture within the current food system. Developing supermarkets with communities can begin, in part, to shift food system power dynamics away from historically racist practices. It is our hope that free-listing can be used as one tool in this process by helping organizations engage communities to identify culturally relevant foods to stock in new supermarkets.

Despite its strengths, this study had several limitations. First, convenience sampling was used to recruit participants for free-listing and therefore the results may not be generalizable outside the study sample. No demographic information other than sex was collected, so we were unable to stratify our analyses to explore potential subgroup patterns (e.g., age, income, participants with children). Although the sample size of 20 participants is com- 
mon and sufficient in free-listing (Quinlan, 2017), it may be beneficial for stores to collect larger samples and more demographic information to explore differences by factors such as race, ethnicity, age, gender, and household make-up (e.g., children or elderly in the home). It is also possible that responses for free-listing may differ based on time of year due to seasonal variation in dietary intake (Ma et al., 2006). Similarly, we only conducted three store observations over a two-month period in winter, and it is possible that the availability and prices of items may differ at various times of the year. Additionally, we did not collect information on the quality (e.g., appearance, taste) of salient items, which may have varied between stores. Finally, this study did not capture the reasons why foods were salient to the participants. We can infer that the items listed were based, at least in part, on the frequency of consumption, given the overall high frequency scores for each item. However, there are likely other influential factors that were not captured by our data collection tool. Future research can build on these results by creating a free-listing tool that directly measures culturally relevant foods, which would likely involve conducting formative research using cultural domain analysis techniques (Borgatti, 1998).

\section{Conclusion}

This study addresses a gap in the literature regarding the methods used by nonprofit supermarkets to engage community members in their operations and decision-making processes. We used a freelisting method to help a nonprofit supermarket identify and further examine the accessibility of salient food items as shared by the study participants. We developed three recommendations for DMG Foods and determined that free-listing is a straightforward method that may be used by organizations with existing supermarkets or those developing new supermarkets. Thus, the present study identifies a method for improving community engagement, particularly among low-income communities and communities of color, and increasing success for new and existing nonprofit supermarkets in urban settings across the United States.

\section{References}

Baltimore City Health Department. (2017). 2017 Neighborhood Health Profile for the Waverlies. Baltimore City Health Department. Retrieved from https://health.baltimorecity.gov/neighborhoods/neighborhood-health-profile-reports

Borgatti, S. P. (1998). Elicitation techniques for cultural domain analysis. In J. Schensul \& M. LeCompte (Eds.), The Ethnographer's Toolkit (Vol. 3) (pp. 1-26). Walnut Creek, CA: Altimira Press.

Brinkley, C., Glennie, C., Chrisinger, B., \& Flores, J. (2019). "If you build it with them, they will come": What makes a supermarket intervention successful in a food desert? Journal of Public Affairs, 19(3), e1863. https://doi.org/10.1002/pa.1863

Caspi, C. E., Pelletier, J. E., Harnack, L., Erickson, D. J., \& Laska, M. N. (2016). Differences in healthy food supply and stocking practices between small grocery stores, gas-marts, pharmacies and dollar stores. Public Health Nutrition, 19(3), 540-547. https://doi.org/10.1017/S1368980015002724

Cooksey-Stowers, K., Schwartz, M. B., \& Brownell, K. D. (2017). Food swamps predict obesity rates better than food deserts in the United States. International Journal of Environmental Research and Public Health, 14(11), 1366. https://doi.org/10.3390/ijerph14111366

Daniel, L., Hinman, S., Harper, K., Ali, S., Gu, Y., Poirier, L., Park, R., Trujillo, A., \& Gittelsohn, J. (In press). Exploring the reasons for low usage and informing strategies to improve use of a non-profit grocery store in Baltimore City. Ecology of Food and Nutrition.

Eisenhauer, E. (2001). In poor health: Supermarket redlining and urban nutrition. GeoJournal, 53(2), $125-133$. https://doi.org/10.1023/A:1015772503007

Gamblin, M. D. (2017). Ending U.S. hunger and poverty by focusing on communities where it's most likely (Briefing Paper No. 31). Bread for the World Institute. Retrieved from https://www.bread.org/sites/default/files/downloads/ending-us-hunger-marlysa-gamblin-march-2017.pdf

Ghosh-Dastidar, B., Cohen, D., Hunter, G., Zenk, S. N., Huang, C., Beckman, R., \& Dubowitz, T. (2014). Distance to store, food prices, and obesity in urban food deserts. American Journal of Preventive Medicine, 47(5), 587-595. https://doi.org/10.1016/i.amepre.2014.07.005 
Gittelsohn, J., Harris, S. B., Burris, K. L., Kakegamic, L., Landman, L. T., Sharma, A., Wolever, T. M. S., Logan, A., Barnie, A., \& Zinman, B. (2016). Use of ethnographic methods for applied research on diabetes among the Ojibway-Cree in Northern Ontario. Health Education Quarterly, 23(3), 365-382. https://doi.org/10.1177/109019819602300307

Gittelsohn, J., Rowan, M., \& Gadhoke, P. (2012). Interventions in small food stores to change the food environment, improve diet, and reduce risk of chronic disease. Preventing Chronic Disease, 9, E59. https://doi.org/10.5888/pcd9.110015

Grigsby-Toussaint, D. S., Zenk, S. N., Odoms-Young, A., Ruggiero, L., \& Moise, I. (2010). Availability of commonly consumed and culturally specific fruits and vegetables in African-American and Latino neighborhoods. Journal of the American Dietetic Association, 110(5), 746-752. https://doi.org/10.1016/i.jada.2010.02.008

Gudzune, K. A., Welsh, C., Lane, E., Chissell, Z., Anderson Steeves, E., \& Gittelsohn, J. (2015). Increasing access to fresh produce by pairing urban farms with corner stores: A case study in a low-income urban setting. Public Health Nutrition, 18(15), 2770-2774. https://doi.org/10.1017/S1368980015000051

Hager, E. R., Cockerham, A., O'Reilly, N., Harrington, D., Harding, J., Hurley, K. M., \& Black, M. M. (2017). Food swamps and food deserts in Baltimore City, MD, USA: Associations with dietary behaviours among urban adolescent girls. Public Health Nutrition, 20(14), 2598-2607. https://doi.org/10.1017/S1368980016002123

Hess, J. D., \& Gerstner, E. (1987). Loss leader pricing and rain check policy. Marketing Science, 6(4), 358-374. https://doi.org/10.1287/mksc.6.4.358

Laska, M. N., Borradaile, K. E., Tester, J., Foster, G. D., \& Gittelsohn, J. (2010). Healthy food availability in small urban food stores: A comparison of four US cities. Public Health Nutrition, 13(7), 1031-1035. https://doi.org/10.1017/S1368980009992771

Ma, Y., Olendzki, B., Li, W., Hafner, A. R., Chiriboga, D., Hebert, J. R., Campbell, M., Sarnie, M., \& Ockene, I. S. (2006). Seasonal variation in food intake, physical activity, and body weight in a predominantly overweight population. European Journal of Clinical Nutrition, 60(4), 519-528. https://doi.org/10.1038/sj.ejcn.1602346

Misiaszek, C., Buzogany, S., \& Freishtat, H. (2018). Baltimore City's food environment report: 2018 report. Retrieved from https://clf.jhsph.edu/publications/baltimore-citys-food-environment-report-2018-report

Petersen, R., Pan, L., \& Blanck, H. M. (2019). Racial and ethnic disparities in adult obesity in the United States: CDC's tracking to inform state and local action. Preventing Chronic Disease, 16, 180579. https://doi.org/10.5888/pcd16.180579

Purzycki, B. G., \& Jamieson-Lane, A. (2017). AnthroTools: An R package for cross-cultural ethnographic data analysis. Cross-Cultural Research, 51(5), 51-74. https://doi.org/10.1177/1069397116680352

Quinlan, M. B. (2017). The freelisting method. In P. Liamputtong (Ed.), Handbook of research methods in health social sciences (pp. 1-16). Singapore: Springer. https://doi.org/10.1007/978-981-10-2779-6 12-1

R Core Team. (2020). R: A language and environment for statistical computing (4.0.0) [Computer software]. R Foundation for Statistical Computing. https://www.R-project.org/

Smith, J. J., \& Borgatti, S. P. (1997). Salience counts—and so does accuracy: Correcting and updating a measure for freelist-item salience. Journal of Linguistic Anthropology, 7(2), 208-209. https://doi.org/10.1525/jlin.1997.7.2.208

U.S. Department of Health and Human Services. (2019). CED Healtby Food Financing Initiative FY 2016. Office of Community Services. https://www.acf.hhs.gov/ocs/programs/community-economic-development/healthy-food-financing

Weller, S. C., \& Romney, A. K. (1988). Systematic data collection. Newbury Park, CA: SAGE. https://doi.org/10.4135/9781412986069

Yao, M., Hillier, A., Wall, E., \& DiSantis, K. I. (2019). The impact of a non-profit market on food store choice and shopping experience: A community case study. Frontiers in Public Health, 7. https://doi.org/10.3389/fpubh.2019.00078

Zhang, M., \& Debarchana, G. (2016). Spatial supermarket redlining and neighborhood vulnerability: A case study of Hartford, Connecticut. Transactions in GIS, 20(1), 79-100. https://doi.org/10.1111/tgis.12142 
Journal of Agriculture, Food Systems, and Community Development

ISSN: 2152-0801 online

https:// foodsystemsjournal.org

\section{Appendix A. Saliency and Frequency of Mentions of All 145 Items Collected During Free-listing}

Italics indicate the foods that were included in the analysis.

\begin{tabular}{|c|c|c|c|c|c|}
\hline Food & Smith's S & Frequency & Food & Smith's S & Frequency \\
\hline Fried chicken & 0.403 & 11 & Cheese & 0.053 & 2 \\
\hline Collard greens & 0.302 & 10 & Clif bars & 0.050 & 1 \\
\hline Shrimp & 0.269 & 8 & Lamb & 0.050 & 1 \\
\hline Steak & 0.169 & 5 & Lamb chops & 0.050 & 1 \\
\hline Salad & 0.141 & 5 & Legumes & 0.050 & 1 \\
\hline Tomatoes & 0.131 & 5 & Mac and cheese & 0.050 & 1 \\
\hline Spaghetti & 0.128 & 5 & Smoothies & 0.050 & 1 \\
\hline Crab legs & 0.126 & 4 & Tacos & 0.050 & 1 \\
\hline Steakfish & 0.124 & 3 & Water & 0.050 & 1 \\
\hline Bananas & 0.119 & 3 & Fried fish & 0.047 & 1 \\
\hline Apples & 0.114 & 4 & Frozen veggies & 0.047 & 1 \\
\hline Beef & 0.113 & 4 & Bottled water & 0.047 & 3 \\
\hline Baked chicken & 0.111 & 3 & Burritos & 0.046 & 1 \\
\hline Broccoli & 0.103 & 6 & Asparagus & 0.046 & 1 \\
\hline Carrots & 0.102 & 4 & Candy & 0.045 & 1 \\
\hline Cabbage & 0.100 & 3 & Kombucha & 0.045 & 1 \\
\hline Pasta & 0.098 & 3 & Baked fish & 0.044 & 1 \\
\hline Onions & 0.098 & 5 & Plums & 0.044 & 1 \\
\hline Strawberries & 0.096 & 3 & Tilapia & 0.044 & 1 \\
\hline Grapes & 0.093 & 3 & Steamed crab legs & 0.044 & 1 \\
\hline Kale & 0.091 & 3 & Hamburgers & 0.043 & 2 \\
\hline String beans & 0.089 & 4 & Enchiladas & 0.043 & 1 \\
\hline Spinach & 0.080 & 3 & Fettucine & 0.043 & 2 \\
\hline Turkey & 0.079 & 3 & Peppers & 0.042 & 1 \\
\hline Watermelon & 0.078 & 3 & Potato chips & 0.042 & 1 \\
\hline French fries & 0.078 & 2 & Rockfish & 0.042 & 2 \\
\hline Pizza & 0.072 & 3 & Croker fish & 0.041 & 1 \\
\hline Sushi & 0.071 & 2 & Red snapper & 0.041 & 1 \\
\hline Cucumbers & 0.071 & 3 & Rice & 0.041 & 1 \\
\hline Eggs & 0.067 & 3 & Turkey bacon & 0.041 & 1 \\
\hline Milk & 0.063 & 3 & Turkey lunchmeat & 0.041 & 1 \\
\hline Catfish & 0.060 & 2 & Lettuce & 0.040 & 2 \\
\hline Baked potato & 0.057 & 2 & Lunch meat & 0.040 & 1 \\
\hline Pineapple & 0.056 & 2 & Soda & 0.040 & 1 \\
\hline Pork chops & 0.056 & 2 & Blueberries & 0.039 & 1 \\
\hline Bread & 0.055 & 2 & Clam chowder & 0.038 & 1 \\
\hline Corn & 0.055 & 3 & Trail mix & 0.037 & 2 \\
\hline Salmon & 0.054 & 2 & Fish & 0.036 & 1 \\
\hline Green beans & 0.053 & 3 & Turkey wings & 0.036 & 1 \\
\hline Cereal & 0.053 & 2 & Almonds & 0.036 & 2 \\
\hline Oranges & 0.053 & 2 & Whitefish & 0.036 & 2 \\
\hline
\end{tabular}




\begin{tabular}{lll}
\hline Food & Smith's S & Frequency \\
\hline Mango & 0.036 & 1 \\
\hline Juice & 0.035 & 1 \\
\hline Mayo & 0.035 & 1 \\
\hline Pretzels & 0.034 & 2 \\
\hline Purple cabbage & 0.033 & 1 \\
\hline Chips & 0.032 & 1 \\
\hline Turkey meatloaf & 0.032 & 1 \\
\hline Potatoes & 0.032 & 3 \\
\hline Frozen spinach & 0.032 & 1 \\
\hline Maple bacon & 0.030 & 1 \\
\hline Ice cream & 0.029 & 1 \\
\hline Brussels sprouts & 0.029 & 1 \\
\hline Spinach and cheese & 0.029 & 1 \\
\hline Peaches & 0.027 & 1 \\
\hline Shellfish & 0.027 & 1 \\
\hline Chicken nuggets & 0.026 & 1 \\
\hline Chicken tenders & 0.026 & 1 \\
\hline Potato salad & 0.025 & 1 \\
\hline Spinach dip & 0.024 & 1 \\
\hline Oodles of noodles & 0.023 & 1 \\
\hline Porgies & 0.022 & 1 \\
\hline Zucchini & 0.021 & 1 \\
\hline Perch & 0.021 & 1 \\
\hline Pork & 0.021 & 1 \\
\hline Radishes & 0.021 & 1 \\
\hline Chicken wings & 0.021 & 1 \\
\hline Coleslaw & 0.021 & 1 \\
\hline Pasta salad & 0.020 & 1 \\
\hline Oatmeal & 0.020 & 2 \\
\hline Corned beef & 0.019 & 1 \\
\hline Granola bars & 0.018 & 1 \\
\hline & & \\
\hline
\end{tabular}

\begin{tabular}{lll} 
Food & Smith's S & Frequency \\
\hline Calamari & 0.018 & 1 \\
\hline Lasagna & 0.018 & 1 \\
\hline Cod & 0.017 & 1 \\
\hline Pickled herring & 0.016 & 1 \\
\hline Fettucine alfredo & 0.015 & 1 \\
\hline Spaghetti sauce & 0.015 & 1 \\
\hline Silk milk & 0.014 & 1 \\
\hline Lima beans & 0.013 & 1 \\
\hline Mushrooms & 0.013 & 1 \\
\hline Turkey burgers & 0.012 & 2 \\
\hline Canned tuna & 0.012 & 1 \\
\hline Almond milk & 0.011 & 1 \\
\hline Fig newtons & 0.010 & 1 \\
\hline Grilled chicken & 0.010 & 1 \\
\hline Grits & 0.010 & 1 \\
\hline Hot peppers & 0.009 & 1 \\
\hline TastyKakes & 0.009 & 1 \\
\hline TV dinners & 0.009 & 1 \\
\hline Gravy & 0.009 & 1 \\
\hline Meatballs & 0.009 & 1 \\
\hline Chicken & 0.008 & 1 \\
\hline Trout & 0.008 & 1 \\
\hline Mussels & 0.006 & 1 \\
\hline Ben and Jerry's & 0.006 & 1 \\
\hline Veggie soup & 0.006 & 1 \\
\hline Pastries & 0.005 & 1 \\
\hline Sausages (breakfast) & 0.005 & 1 \\
\hline Buffalo wings & 0.004 & 1 \\
\hline Peanut butter & 0.004 & 1 \\
\hline Frozen okra & 0.003 & 1 \\
\hline Hotdogs & 0.003 & 1 \\
\hline & & \\
\hline
\end{tabular}


Appendix B. Saliency and Frequency of Mentions of All 35 Stores Collected During Free-listing Italics indicate the stores that were included in the analysis.

\begin{tabular}{|c|c|c|}
\hline Store & Smith's S & Frequency \\
\hline Giant & 0.7031 & 20 \\
\hline$D M G$ & 0.4669 & 17 \\
\hline Safeway & 0.1784 & 6 \\
\hline Aldi & 0.1479 & 4 \\
\hline Walmart & 0.1162 & 6 \\
\hline Family Dollar & 0.1123 & 4 \\
\hline Trader Joes & 0.0704 & 2 \\
\hline Lexington Market & 0.0615 & 3 \\
\hline Corner store & 0.0602 & 3 \\
\hline Bi-Rite & 0.0556 & 2 \\
\hline MOMs & 0.0556 & 2 \\
\hline Farmers market & 0.0464 & 2 \\
\hline Food Depot & 0.0417 & 3 \\
\hline Redner's & 0.0417 & 1 \\
\hline Whole Foods & 0.0397 & 2 \\
\hline NE Market & 0.0347 & 1 \\
\hline Save-a-lot & 0.0347 & 2 \\
\hline Sprouts & 0.0324 & 1 \\
\hline H-Mart & 0.0278 & 1 \\
\hline Shoppers & 0.0278 & 1 \\
\hline Family farm & 0.0255 & 2 \\
\hline Convenience store & 0.0208 & 1 \\
\hline Montgomery Street Market & 0.0208 & 1 \\
\hline Sam's club & 0.0208 & 1 \\
\hline Harvest Fare & 0.0179 & 1 \\
\hline Amazon (Online) & 0.0139 & 1 \\
\hline Dollar Store & 0.0139 & 1 \\
\hline Hamilton Market & 0.0139 & 1 \\
\hline Northeast Market & 0.0139 & 1 \\
\hline Food Lion & 0.0104 & 1 \\
\hline $\mathrm{H}$-mart & 0.0104 & 1 \\
\hline Rite Aid & 0.0093 & 1 \\
\hline Market & 0.0069 & 1 \\
\hline Arabber a & 0.0046 & 1 \\
\hline Target & 0.0046 & 1 \\
\hline
\end{tabular}

a Arabbers are street vendors particular to Baltimore who sell fruits and vegetables from colorful, horse-drawn wagons; see https://en.wikipedia.org/wiki/Arabber 